\title{
Assessment of Applying Global Instruments in Nongovernmental Organizations for Environmental Security and Sustainable Development in Developing Countries
}

\author{
Mekonnen Hailemariam Zikargae \\ Bahir Dar University, Faculty of Humanities, Department of Journalism and Communication, Bahir Dar, Ethiopia \\ Correspondence should be addressed to Mekonnen Hailemariam Zikargae; kebreabmeko2a@yahoo.com
}

Received 28 February 2020; Revised 8 December 2020; Accepted 23 January 2021; Published 10 February 2021

Academic Editor: Ahmed Rachid

Copyright (c) 2021 Mekonnen Hailemariam Zikargae. This is an open access article distributed under the Creative Commons Attribution License, which permits unrestricted use, distribution, and reproduction in any medium, provided the original work is properly cited.

\begin{abstract}
Background. Environmental challenges are overwhelming the global communities. Thus, the purpose of the study is to explore how instruments used by the nongovernmental organizations are applied for environmental security and sustainable development in Ethiopia. It addresses issues of how environmental education in context is working to instill the knowledge, skills, awareness, and attitudes of the stakeholders. Recent discussions of the African Union Summit 2020, Africa Agenda 2063, Davos 2020 World Economic Forum, United Nations Agenda 2030, and the Green Economy Strategy in Ethiopia have strongly sought to strengthen environmental education as an instrument of global and local sustainability of the environment and development. Here, the study collected pieces of evidence from environmental programs of a nongovernmental organization in Ethiopia. The study focused on a nonformal environmental education, based on the frameworks of the agreements and declarations where Ethiopia is a contracting party. The frameworks are guiding concepts to investigate the phenomenon. Methods. The study used a thematic analysis based on empirical studies. Specifically, empirical studies from primary and secondary sources on the implementation of environment and forest development programs of the organization are crucial to providing a concrete presentation. Results. Empirical pieces of evidence show that the organization plans, projects, and performance reports were found inconsistent with the frameworks of international agreements and national policy. The empirical study also shows that environmental education is not well considered and institutionalized in the organization's project planning. Environmental education strategies are not explicitly visible while planning the projects. Moreover, in some implementation strategies of the organization, there was inconsistency in using environmental education as a strategic instrument to improve environmental security and quality. Conclusion. The organization's environmental performance was deep-rooted to improve the status quo in the living community. However, the utilization of environmental education was discovered to be minimal. Thus, stakeholders and the organization take the advice to integrate into the entire cycle of the project.
\end{abstract}

\section{Introduction}

The aim of this study is to explore how instruments used by the nongovernmental organizations are applied for environmental security and sustainable development in Ethiopia. In Ethiopia, environmental challenges and climate change problems are deep-rooted economic, social, and environmental obstacles [1]. Specifically, dependence on rain-fed agriculture, low economic development, deforestation, land degradation, and larger as well as denser human settlements have been alarmingly increasing vulnerability to environmental stressors in Ethiopia. The author strongly argues that global and local environment and development challenges have been adversely affecting the mainstreaming economy and sociopolitical situations of the country. The problem could also get both global and local attention when investigated very carefully. To investigate it thoroughly, this study focuses on environmental education as an instrument to understand the process of environment programs implemented by a local nongovernmental organization 
(NGO) in Amhara national regional state. The organization is known as Organization for Rehabilitation and Development in Amhara (ORDA). This study also considers the implementation of an environment and forest development program (EFDP) in the region. Studies confirm how education is used as a tool to combat various environment and development related problems [2]. In Ethiopia, the contribution of the NGO is one step to support the government's commitment to the improvement of environmental security, forest development, and climate change challenges. However, the Ethiopian government lacks coordination among the different stakeholders such as local NGOs, local development organizations, and environment promoters [3-8]. Therefore, this study looks at the practices of ORDA to combat environmental challenges and its implication to sustainable development.

Environmental education, partly, is a means and instrument to empower the local community [9]. It could be suggested and used as experiential learning that develops the knowledge, skills, and capacity of the community who engaged in environmental activities. However, environmental education in the program planning and implementation has got lesser attention to getting into the environment and forest development program. Therefore, the communitybased integrated and multilevel approach is crucial to ensure experiential learning in its nonformal education to create and increase the understanding and awareness of the society. As a result, knowing the status quo of environmental education in the current global and local environmental challenges and climate changes is essential and desirable for sustainable development in Ethiopia. The magnitude and level of intervention could be sought in its status quo. To this end, the literature shows that the deep-rooted causes of environmental challenges in Ethiopia are the lack of sufficient environmental information and awareness. It is emphasized that these factors are the underlying causes of severe environmental degradation in Ethiopia. Other root causes include the declining trend in the provision of outdoor environmental education; inadequate levels of factual knowledge among the community and variations in knowledge levels and attitudes are partly the major problems. In order to investigate whether the abovementioned factors persist or not, the main objective is aligned to address the questions mentioned hereinafter. Therefore, the study specifically seeks to answer two questions.

Q1: How does ORDA consider environmental education as a strategic tool to engage its stakeholders?

Q2: What are the opportunities and challenges faced by ORDA in applying environmental education as a strategic communication tool?

Limitations. There are no sufficient studies in the past to this date, which is the major limitation of the current study. In contrast, the current study shows how these international instruments used by NGOs are applied in Ethiopian environmental policy and implementation contexts. The current study contributes to the sustainable efforts of the community in the community projects. It also indicates limitations for future action plans for similar community projects. The current study explains that inadequate levels of factual knowledge among the community and variations in knowledge levels and attitudes are partly the major problems. The motivation for the current study or the major emphasis in such study is the discovery of ideas, perspectives, or insights from the existing knowledge and experiences.

\section{Conceptual Frameworks of Environmental Education}

This part explains the application of the frameworks for international and local instruments to environmental education. The researcher defines environmental education as a general form of educational and international instruments to address and improve environmental issues in a global and local context. Here, the researcher tried to narrow the perspectives to the nonformal environmental education used and practiced in the outdoor of environmental community contexts whereas formal education is beyond the scope of this study. In the end, the study links the conception of environmental education with sustainable development. Education, in general, and environmental education, in particular, are an integral part of sustainable development and environmental communication. Environmental education, environmental communication, and sustainable development have strong relationships. These themes are important approaches and strategies while dealing with environmental challenges and issues. The UN conference, for instance, conducted at different times emphasizes the strong link between environmental education and sustainable development [10]. Thus, the concept of environmental education gained momentum at the UN conference in Stockholm in 1972 to overcome environmental challenges [11]. The conference mainly incorporated a holistic view that motivated 175 countries to focus on environmental challenges and development issues. These countries were expected to include environmental and sustainable development issues in their policy as a cross-cutting issue that reaches different international and local audiences. Let us look at what environmental education means.

2.1. Definitions of Environmental Education. Defining the field of environmental education is important to make the areas of interest and familiarity with the concept of environmental education. Besides, it could be possible to operationalize and consolidate the concept of environmental education. This attempt helps us to conceptualize where it appeared in the educational perspectives. For these reasons, the consecutive definitions of environmental education in the context of environmental activities attempted to capture some common essence and understanding. The major definitions of environmental education are found in academia, policy, and agreements. We can draw a common understanding of it from the documents. The common understanding aimed to leverage stakeholders' knowledge, awareness, skills, behaviors, and understanding of the environmental challenges and issues. Individuals' experiential 
learning process could enhance their attitudes, motivations, and commitments to undertake decisions and appropriate actions regarding environmental challenges and issues. In this regard, there are different views on the definition of environmental education. Those views could be endorsed to conceptualize environmental education.

The first environmental education is stated in the Tbilisi Declaration at the UN conference developed by UNESCO environmental educators in 1977. Here, environmental education is defined as a learning process. This process is directly related to experiential learning. The learning process has different benefits. The learning process is assumed to increase and boost up stakeholders' knowledge and awareness about the environment and associated challenges and issues. Besides, the learning process helps the community to develop the necessary skills and expertise to address the challenges and impacts of environmental challenges that would affect sustainable development. Moreover, it fosters the attitudes, motivations, and commitments of stakeholders to make informed decisions. The legitimate decision could lead to taking on responsible action [12].

The second definition stated by [13] saw environmental education as a universal approach to education. Environmental education in this regard is aimed at developing a world population awareness. The third definition aimed to increase global awareness. This definition calls for the global effort. It contributes toward the knowledge, skills, attitudes, motivations, and commitments of citizens to work individually and collectively toward a solution of current problems and prevention of new ones [14].

Still, some other definitions worth mentioning are that environmental education could be a lifelong learning process. The lifelong learning process increases an individual's awareness of, relationship with, and dependence on the environment and its systems [11]. Accordingly, the ultimate definition of environmental education focuses on the education and learning of children; however, environmental education can, and should, be a lifelong process. Therefore, environmental education requires a lifelong learning process to get knowledge and skills and develop attitudes, motivations, and commitment to handle environmental challenges and sustainable development. However, this study wants to capture environmental education based on noncurricular and nonformal education.

Therefore, the above definition core learning process ultimately leads the stakeholders to develop awareness, skills, attitudes, motivations, and commitments.

2.2. Goals of Environmental Education. The terms mentioned in the above definitions envisage and capture the basic goals and outcomes of environmental education. However, environmental education is more than learning about the environment. It is about changing behavior and instills learners' knowledge about the environment, developing positive attitudes toward the environmental challenges, competency in citizen action skills, and a sense of empowerment and legitimacy [15-17], thus, promoting environmental awareness, behavior, and eventually action through education, and raising stakeholders' awareness and training. These are some of the ultimate goals of environmental education [18]. Others also emphasized the goals of environmental education that include awareness, behaviors, knowledge, attitudes, skills, and actions of human beings toward their environment $[14,19]$. Here, the integrated and multilevel approach to bring a behavioral change at both the individual and societal levels is important to upbeat the stakeholders' skills and knowledge about the environmental challenges and issues. Environmental education imparts knowledge and creates experiences to change beliefs, attitudes, and most importantly behavior [20]. Getting knowledge consecutively brings changes in attitude and behavior. In the international framework, the Belgrade Charter adopted at this conference provided a widely accepted goal statement for environmental education. To sum, the goals of environmental education focus on promoting environmental awareness and raising stakeholders' awareness and pieces of training to uphold stakeholders' knowledge, behavior, skills, motivations, and attitudes.

2.3. Approaches of Environmental Education. Different approaches or strategies are considered for environmental education to address environmental challenges and issues. The environmental education approach is a multilevel approach and has continuity. The process of environmental education can occur through formal, nonformal, and informal approaches or settings. There are noncurricular environmental education approaches. According to $[11,19]$, the nonformal approach targets special programs outside a school system for adults and communities. This approach could be activities or programs provided to the community, organizations, youth groups, and nature centers as a lifelong learning process.

Another approach focuses on obtaining environmental professional skills with different professional disciplines. This includes stakeholders' participation in workshops, volunteering, role play, field trips or holidays, and environmental days. It is also noted that environmental education involves the dissemination of information without an organized educational structure. And typically, it includes learning about the environment through the media, personal reading, everyday experience, and interactions with other people. This type of learning entails experiential learning.

2.4. How It Evolved? The evolution of environmental education began in the $18^{\text {th }}$ century with Rousseau and evolved into the conservation movement in the 1920s and 1930s. Thus, the modern aspects of environmental education started with nature study. Environmental education, from 1970 to the current form, passed different types of concepts and forms. A different time international meeting contributed to the formulation and adoption of environmental education. These trends could be summarized and depicted in the diagram shown in Figure 1.

In the global education form, development of education, values of education, and action of research were the 


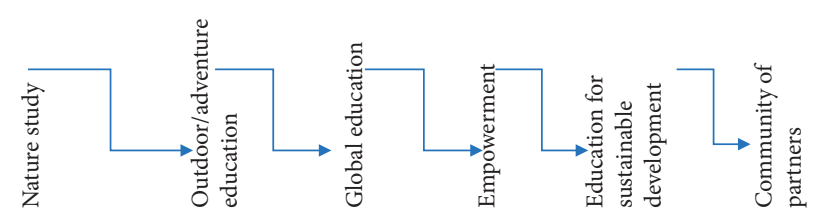

Figure 1: Different aspects of emphasis on environmental education [21].

dominant forms and concepts of environmental education. Participatory communication is a form of environmental education for a sustainable future. In the current form, the concept of environmental education is seen as the collaboration of a community of stakeholders working together to solve ecological problems.

\subsection{Environmental Education Nexus Sustainable} Development. Different initiatives on environmental education for sustainable development are taking place within a global context. It was discussed as an educational issue at the UN Conference on the Human Environment in Stockholm. It took center-stage at the UNEP Intergovernmental Conference on environmental education in Tbilisi. Environmental education played a central role in the discussions at the 1992 UN Conference on Environment and Development at Rio de Janeiro which paved the way for hot debates and actions on the environmental challenges. Still, another issue has become the touchstone and the milestone against which the global action is judged, Agenda 21. In this regard, Chapter 36 of Agenda 21 recognizes education as the major vehicle and instrument for arriving at a sustainable, democratic, and globalized future. In general, education, including formal education, public awareness, and training, could be recognized as a process by which stakeholders' can reach their fullest potential. Moreover, education was treated on Agenda 21 as critical for promoting and supporting sustainable development. Above all, it improves the capacity of the stakeholders to address environmental challenges and development issues [22]. Therefore, the link between environmental education and sustainable development is critical to enhance and leverage environmental protection and security. In another scenario, the participants assert that the World Economic Forum, Davos 2020, Annual Meeting in Davos-Klosters was the foremost creative force for engaging the world's top leaders in collaborative activities to shape the global, regional, and industry agendas at the beginning of forthcoming each year.

\section{Materials and Methods}

The methodology used for this study is qualitative which is based on theoretical and empirical studies. This study used a thematic analysis. The analysis is based on the information collected from secondary sources of the organization [23-30]. Besides, international agreements were used for analysis. Moreover, different legal frameworks and agreements are considered for analysis. The thematic document analysis approach is believed to assist and empower the researcher to have an in-depth understanding of the purported investigation [31]. The guiding principles are the conceptual approaches that discuss the definitions, goals, and approaches of environmental education. In addition, the research qualitatively attempts to look at the link and the implication of environmental education to sustainable development. There are some differences exhibited between past research and current studies. In the first place, I tried to search, with a vacuum cleaner, the most related research to the current study. Some recent studies focus on school curriculum environmental education that, to some extent, considers outdoor environmental education still underresearched. The school's formal environmental education is criticized because it lacks connection to the outdoor nonformal environmental education.

The current research focus lacks connections to a previous study for which very limited research was done in my focus area. So, the current study, particularly, to Ethiopian cases (no other research found till this date), could be treated as one of my Ph.D. study themes in environmental communication. However, the current study relies on the nonformal environmental education that focused on community-based environmental projects on which it did not consider formal environmental education. Some available research focused on environmental challenges at a global, regional, and local level. Specifically, the practice of ORDA is critically examined. The time framework for the documents is 1991-2020. Some documents are archived and collected online. Some others are collected from ORDA. There were several documents used for the current study. However, the major ones include the policy documents, project documents to the donors, strategic plans, organizational reports, and agreements which are considered to be the major concern of this study. The study questions are twofold. The case study of ORDA considers how environmental education is used as a strategic tool to engage its stakeholders. It, also, investigates the challenges faced by ORDA in applying environmental education as a strategic communication tool. They could be discussed in the current empirical study.

A case study design is appropriate to make an in-depth empirical inquiry that investigates, explores, and describes environmental education within its codified contexts [32]. Therefore, the exploratory and descriptive qualitative case studies are selected to instigate experiences of environmental education from existing documents of environmental education concerns of ORDA. The major emphasis in such study is on the discovery of ideas, perspectives, or insights from the existing coded knowledge and experiences of the organization emerged from the documents [23-30]. The case for study is ORDA. There are several programs headed by ORDA. For the purpose of this study, the researcher considered the case of environment and forest development 
program. Thus, the case focuses on the performance of the ORDA with regard to community-based projects on the specified issue. At the end, this paper focuses on describing the practical experiences through the document-based thematic analysis.

\section{Results and Discussions}

ORDA is a nonprofit organization working on communitybased environmental projects in Amhara regional state to ensure environmental security and livelihoods of the community. This study scrutinizes the legal frameworks attempted to guide to tackle global and local environmental challenges. Besides, it reviews global environmental challenges and associated measures. Moreover, the review narrows to the Ethiopian environmental challenges and some of the concerns to combat the challenge. Furthermore, this part describes the commitment of a local environment and development toward environmental challenges. Further, this part reviews the practice of environmental education by ORDA in community-based projects. Last but not least, it considers the factors that affect the practice of environmental education in ORDA. The result indicates that ORDA's environmental education strategy since its establishment in 1993 could be manifested in many ways. These include training, learning forum used for scaling up, documenting the experiences of opportunities, challenges, and knowledge management, and institutionalizing an approach used for the purpose of scale-up, empowerment of the community, and knowledge management to gear as input toward another plan. However, the overall investigation of this study shows that there exists a low level of knowledge management and a strategic role in building capacities of the regional community in scaling-up of organizational capacities in project design, planning, monitoring, and evaluation. Still, monitoring and evaluation results were not seriously considered for learning and as the management tool for further improvement as one of the learnings and legitimate strategy of the organization. Besides, the overall investigation of environmental education in the stated above international and local frameworks shows that environmental education is not well institutionalized in a local NGO as of ORDA environmental project practices.

4.1. Legal Frameworks: Local and International Perspectives. This part deals with international conventions, agreements, conferences, and protocols on environmental sustainability, environmental education, and sustainable development. In addition, it discusses the relationship between environmental sustainability and sustainable development emphasized in the documents. There are general statements adopted by most countries of expressing interest and their willingness to improve their environmental behavior. The long and painful negotiations on climate change and problems also provide evidence of the difficulties associated with achieving large, stable, and substantial international environmental agreements. Then, a growing recognition has been shown across the world that citizens should play a role in informing and shaping environmental policy [9]. The World Summit on Sustainable Development held in Rio de Janeiro indicates that many countries have formulated strategic environmental sustainability policies. The policies include environmental concerns to develop long-term environmental interventions. There, stakeholders' involvement in the theme of environmental protection and sustainable development was highlighted at the UN conference on the sustainability of the environment and development. In addition, it was given due attention during the World Summit on Sustainable Development in Johannesburg [33].

Likewise, stakeholders' participation has also been part of a legal component of the development of Ethiopia. According to GEF Portfolio Identification Document, the government has prioritized ensuring environmental sustainability in its development plans and programs. The overall policy goal is twofold: one is to improve the clean and healthy environment for all Ethiopians; the other is to promote both sustainable cultural and economic development of the country for the current and future generations. This can be drawn with the assumption of ensuring and maintaining sustainable development [34]. The policy raises issues to ensure the empowerment and participation of the people and their organizations at all levels in the protection of environmental challenges. Accordingly, the major demand of the policy emphasizes government commitment to raise stakeholders' awareness and to promote the understanding of the essential linkages between the environment and development which could not undermine the participation of the stakeholders in environmental challenges and issues.

Therefore, instruments like environmental laws, regulations, executive orders, and treaties explicitly call for effective and meaningful stakeholders' participation in environmental decision-making processes and legitimacy. It is also a legal requirement or prerequisite for governmental and local NGOs' decision-making [35]. In addition, every citizen has the right to live in a healthy environment and should protect the environment. Recently, the Davos 2020 World Economic Forum committed to raising and debated the issue of environmental challenges and climate change. The Davos 2020 World Economic Forum discussed how to save the planets. The participants take utmost care to mitigate our environmental impact. To this end, the current debate, commitment, and strategy of African Union Summit 2020, the Blue Economy Strategy, Agenda 2063, Davos 2020 World Economic Forum, UN Agenda 2030, and the Green Economy Strategy in Ethiopia have sought to strengthen the approach of environmental education as a concern of the sustainability of environmental security and development in Ethiopia.

4.2. Global Environmental Challenges. Environmental challenges and climate changes are the overwhelming and long-term debate. They have been global agenda as a fact of affecting the sociopolitical and economy of the majority of the countries. There were many concerns and commitments made during different meetings. The UN conference held in 
Tbilisi in 1971 had shown a strong link between environmental education and sustainable development. Again, the UN conference in Stockholm in 1972 developed a strategy to overcome environmental challenges. Another agreement instrument was the World Summit on Sustainable Development held in Rio de Janeiro, 1992, which attempted to formulate strategic environmental sustainability policies for the involvement of the stakeholders in environment and development activities. Still, Agenda 21 was an important instrument for the debate on environmental challenges and sustainable development. The recent debate of the Davos 2020 on the World Economic Forum considered environmental challenges and climate change as the major agendas of the debate. The African Union agenda 2063 meeting and its report are of its kind to show the grievances of environmental challenges that could hamper sustainable development in the region. Scholars argue that "the majority of people lack the ability to think critically and systemically about the causes of key challenges such as climate change, water scarcity or pollution, biodiversity loss" [36].

Likewise, a very recent happening emanated from China shows that the world is not a separate entity and global challenge free and it would rather be one village that could be affected and threatened by, for example, the Novel Corona Viruses with its disease name called COVID-2019 which currently originated from and paralyzing China and threatening the rest of the world.

4.3. Environmental Challenges in Africa. Yet it is still difficult to find environmental studies in Africa [37]. Environmental challenges are global by their nature; however, there could be serious development issues in Africa. Africa is considered a land of innovation and opportunity but Africa inherited a hazardous-living environment. The most critical problems are the danger of deforestation, soil erosion, desertification, wetland degradation, and insect infestation [38]. "Efforts to deal with these problems, however, have been handicapped with a real failure to understand their nature and possible remedies" (p.4). There is also limited literature on the study of environmental challenges in Africa. The situation is diverse and complex in Africa and so does in most parts of Sub-Saharan Africa. A scholarly report indicates that "social and economic inequality is increasing and human vulnerability due to environmental change is also increasing and manifesting itself into disasters in many parts of the continent" [39].

At Africa and the international level, the recent events of the Davos 2020 meeting and African Union Summit 2020 are strongly allied with and discussed the sustainability of the environment and development. On the one hand, the Davos 2020 World Economic Forum discussed the serious environmental challenges and climate change that are overwhelming the global community. On the other hand, another meeting held in Addis Ababa as the African Union Summit 2020 is favored and advocated the development of a sustainable Blue Economy as of its strategic importance to the implementation of Agenda 2063 flagship projects that link and discuss the environmental challenges and development issues. The Blue Economy Strategy enables Africa to guide the development of an inclusive and sustainable Blue Economy. This is believed to become a significant contributor to continental transformation, growth, and environmental sustainability. Thus, environmental sustainability, social sustainability, and economic sustainability are the three pillars of Blue Economy [40], whereas, at the Ethiopian level, there is a strong high-level government commitment to a green economy and greening agenda within the context of accelerated industrialization [4]. In my conclusion, the ORDA's fourth revised strategic plan is strongly allied with the Africa Agenda 2063 and UN Agenda 2030. ORDA, as part of environmental education, has been developing experience sharing, stakeholders' workshops, review meetings, and capacity building and awareness of creating training [28]. Still, the ORDA's evaluation, monitoring, and learning report indicate that the organization accumulated its knowledge regarding the status of ORDA's project from separate ORDA operational areas [26].

4.4. Environmental Challenges in Ethiopia. The Environment, Forest, and Climate Change sectors have been struggling to develop a strategy to approach the situation in Ethiopia. Issues in these sectors are getting more complex and call for knowledge-based responses. Thus, project planning matters in the context to alleviate the problem. However, despite comprehensive guidelines and directives, effective environmental enforcement remains challenging. Major challenges concerning the enforcement of environmental laws include environmental preservation, climate change, high population growth, scientific uncertainties, usage of outdated technologies, and lack of political commitments, societal attitudes, and poverty. On the one hand, Ethiopia is an internationally visible country on environmental campaigns more than countries with better domestic achievements on environmental protection. The international political leadership for green economy and environmental protection continued through its momentum. The current green legacy campaign continued throughout the fiscal year which is another scenario to tackle environmental challenges and climate change situation in Ethiopia. However, until recently, the country's domestic performances are not fully considered due to policy gaps and lack of political will and commitment [41]. On the other hand, some argue that the environmental issues of Ethiopia serve the political agenda more than the genuine environmental concern. Therefore, policy gaps and low political willingness are the remaining challenges to improve environmental qualities. Besides, the negligence to consider international environmental education as instruments is the most challenging and the dark side to improve environmental security in Ethiopia.

4.5. Environmental Education Practice in Ethiopia. Since 2015, the Ethiopian policy considers environmental education and protection as one of the cross-cutting issues. Its purpose was to raise public awareness and promote understanding of the essential linkage between the 
environment and development [42]. Environmental issues are common in each empirical research work and this study. Today, several studies have been conducted by different scholars on formal and nonformal environmental education to develop the understanding and awareness level of a segmented part of the community on environmental challenges. The environmental education research shows the nonexistence of an intimate understanding of the value of natural resources. The community also showed a lack of awareness about the environmental degradation, low capacity to address environmental degradation, and inadequate level of factual knowledge [2, 5, 43-49]. There are a number of studies carried out in Ethiopia concerning environmental and development challenges. However, the nonformal lifelong learning environmental education among the community could get less attention in most environmental and development projects and programs. ORDA is one of the local NGOs that is established in Ethiopia and engaged in environmental and development programs and projects. Thus, this study is carried out on ORDA's environment and forest development program. I would like to see studies that are related to this study and their perspective research gaps. Some of these studies for the purpose of the current case are selected, summarized, and compared with the current study as follows.

To begin with, a study [45] focuses on nature/environment in elementary environmental science textbooks and the comparison between two-third of graders at a private Ethiopian school with an antiutopian and a utopian perspective on the environment. Accordingly, their research considered the formal school system that mainly considers the formal environmental education curricula. However, the current study primarily focused on environmental education with nonformal and informal environmental education that could not consider the school curricula. In the meantime, both studies use and emphasize environmental education to check the human and environmental interaction and its related challenges in contemporary Ethiopia for the improvement of the quality of the environment and human life.

Still, others conducted a study on Ethiopian students' relationship with the environment [50]. The interaction of the students' in the environment is emphasized. The research used different populations and context but considers environmental issues which are similar to the current study. In addition, both studies used environmental and human interaction as the center of their discussion.

Still, some others [49] conducted research on the challenges and opportunities paved by curricular environmental education at a teacher education college level. In light of the above empirical studies, the writer of this article could barely find research conducted on nonformal environmental education strategies aligned with the execution of environmental programs or projects.

4.6. ORDA's Commitments and Practical Experiences. ORDA was founded in 1984 in response to rural poverty as the Ethiopian Relief Organization which was legally registered as a local NGO in 1991. Currently, the mission of
ORDA [29] is "empowering poor communities, and their institutions to achieve livelihoods and environmental security in the Amhara region" (P.9). Previously, the situation of Ethiopia was not peaceful since 1984. As a result, ORDA focused on displacement and rehabilitation of the Amhara region until 1993. In this implementation period, the development strategy of ORDA engaged in emergencies at the cost of environmental consideration. From 1993 until 1997, ORDA exclusively had been working on development activities.

However, in 1997, ORDA planned the first strategic plan of the organization which was implemented in the years 1997-2003 [25]. The plan focused on natural resource protection, agricultural development, rural water supply, rural feeder road constructions, resettlement, and rehabilitation of migrants, emergency food aid, and food store construction. ORDA since then considered and integrated environmental issues in the development process. This aimed to meet a government policy that focused on environmental protection and rehabilitation strategy. At the time, the conditions were suitable for NGOs, relief, and rehabilitation activities. After its implementation, it was reported that there was a low commitment of the staff, high turnover of the staff, and the problem of addressing these issues. Thus, the strategic plan document was not strictly followed and applied. Moreover, there was no environmental education approach used as a major participatory tool to empower the stakeholders in that context. These are major factors that hindered the mission of the ORDA on environmental issues and its development processes.

Secondly, during its second strategic plan of the organization and in its implementation years 2004-2008, the organization [29] identified priorities in agricultural development and environmental protection, forest resource development, water resources development, capacity building, and community development, disaster prevention, and relief programs. In this, strategic plan environmental issues got much more attention than the first strategic plan of ORDA.

Thirdly, the third strategic plan of the organization in its implementation years of 2009-2013 [23] reduced and focused on its priorities to natural resource development, water resource development, and food security, and agricultural program. However, natural resource development and environmental protection are some of the areas of intervention of ORDA to enhance the livelihood of the people and ensure environmental security in the region. The intervention of ORDA could be highly motivated by empowered stakeholders or community participation and is strongly described by the ORDA in its third strategic plan performance report [30].

As part of ORDA's strategic plan, environmental education is one of a strategic community empowerment tool to the participants of the project implementation as "training of trainers on Adult Learning Principles and Communication was provided to Woreda sector office and ORDA project staffs in view of realizing the development approach effectively and facilitate community empowerment" ([30], p.71). Another important issue of environmental education is a 
learning forum used for scaling-up purposes. The learning program in the empowerment of the community to achieve environment and livelihood security is stated as "the already started learning forum is a good stepping stone."

A learning forum was organized in April 2012 with the objective of "scanning ORDA's development approaches and seeing possibilities of scaling-up" ([30], p.72). However, the report criticizes the limited participation of the targeted group or community. To sum up, the learning and scalingup strategy using ORDA's learning forum and documenting the experiences of opportunities and challenges faced during its progress of project implementation was strongly the asset of ORDA. ORDA strongly believes that knowledge management can improve the overall generation of information and data capture, storage, dissemination, and scaling-up. Other points to mention are participating women, especially, in the learning process and dissemination of best practices could be the asset of ORDA. Still another asset is that learning forums are quite essential to institutionalize an approach(s) helping more to achieve the vision of ORDA.

However, ORDA learned many challenges. First, a low level of knowledge management and learning could be the input for further improvement for ORDA's strategic thinking and dynamism. Second, there was a low level of a strategic role in building capacities of the regional community in scaling-up of organizational capacities in project design, planning, monitoring, and evaluation. The monitoring and evaluation results were not seriously considered for learning and as the management tool for further improvement as one of the learning strategies of the organization.

Finally, the fourth strategic plan of the organization (2014-2018) was implemented for the years 2014-2015. However, to meet the Ethiopian government development policy, the fourth strategic plan was revised and planned as a fourth revised strategic plan (2016-2020), which is currently in its implementation phase of the project. The fourth strategic plan, in particular, was revised to meet the government Growth and Transformation Plan II (GTP-II). This strategic plan is very much appreciated and has given due attention to its mission to work on EFDP.

The plan emphasizes and specifically addresses the Sustainable Development Goals (SDGs). One of the goals is named Goal-13 that takes urgent action to combat climate change and its impacts. The other goal is Goal-15 which aimed to protect, restore, and promote sustainable use of terrestrial ecosystems, sustainably manage forests, combat desertification, and halt and reverse land degradation and halt biodiversity loss which is directly aligned with ORDA's vision and mission. Remarkably, the fourth strategic plan consistently, at the local level, allied with national and international agendas. Currently, ORDA's program consists of different programs which are categorized as the environment and forest development, water, and irrigation program, agriculture, and disaster risk management programs, youth enterprise, private-sector development, and gender unit. Inconsistent with the organization's subprograms, the study focuses on five subdivisions of its EFDP of ORDA that is aimed at establishing environmental security in the
Amhara region. This program is also subdivided into forest development, biodiversity, watershed development, soil, and water conservation, and climate resilience.

On the one hand, the Davos 2020 World Economic Forum discussed the serious environmental challenges and climate change that are overwhelming the global community. On the other hand, another meeting held in Addis Ababa as the African Union Summit 2020 is favored and advocated the development of a sustainable Blue Economy as of its strategic importance to the implementation of Agenda 2063 flagship projects that link and discuss the environmental challenges and development issues. The Blue Economy Strategy enables Africa to guide the development of an inclusive and sustainable Blue Economy. This is believed to become a significant contributor to continental transformation, growth, and environmental sustainability. Thus, environmental sustainability, social sustainability, and economic sustainability are the three pillars of the Blue Economy [40]. At the Ethiopian level, there is a strong and ambitious high-level government commitment to a green economy and greening agenda within the context of accelerated industrialization [4].

Therefore, ORDA's environmental education strategy since its establishment in 1993 could be manifested in many ways. These include training, learning forum used for scaling-up, documenting the experiences of opportunities, challenges, and knowledge management, and institutionalizing an approach used for the purpose of scale-up, empowerment of the community, and knowledge management to gear as input toward another plan. However, the overall investigation of this study shows that there exists a low level of knowledge management and a strategic role in building capacities of the regional community in scaling-up of organizational capacities in project design, planning, monitoring, and evaluation. Still, monitoring and evaluation results were not seriously considered for learning and as the management tool for further improvement as one of a learning and legitimate strategy of the organization.

\subsection{Factors Affecting Environmental Education in Ethiopia.} The current debate, commitment, and strategy of African Union Summit 2020, the Blue Economy Strategy, Agenda 2063, Davos 2020 World Economic Forum, UN Agenda 2030, and the Green Economy Strategy in Ethiopia have sought to strengthen the approach of environmental education as a concern of the sustainability of environmental security and development in Ethiopia. However, a declining trend in the provision of outdoor and lifelong experiential learning community-based environmental education could be in favor of environmental education. Specifically, to address the societal problems, the outdoor educational strategy is crucial. Scholars scrutinize the fact that "the major reason behind formulating national education policies is the desire to address diverse societal problems" (p.140) [51]. There have been also observed inadequate levels of factual knowledge among the rural community and urban dwellers. Moreover, there have been variations in knowledge levels and attitudes among the community. Thus, the factors are 
related to a system development that considers community in a context-based environmental education approach. In the meantime, environmental stakeholders' awareness is shaped by economic, social, professional, religious, ethnic, cultural, and educational factors. Still, other studies indicated the major problem or factors of conducting environmental education as a strategy [2] found that unfavorable learning environment regarding infrastructure, socioeconomic, lack of initiatives, students' family background, and local community factors and poor coordination between different stakeholders are factors that affect the practice of environmental education and the responses to local environmental needs. Therefore, contextual factors are very much important to consider in the planning phase of the projects.

\section{Conclusion}

Environmental challenges and climate changes are the overwhelming and long-term global challenge and agenda. Above all, it has strongly been affecting the sociopolitical and economy of the majority of the developing countries. The world is not a separate entity and it would be rather one village that could be affected by, for example, the Novel Corona Viruses with its disease name called COVID-2019 which currently originated from and paralyzing China and threatening the rest of the world. It is certainly a global calamity. It also argued that it has an impact on long-term ongoing environmental issues impacting climate change and natural resource degradation. Likewise, environmental challenges and climate change never differentiate one country from another country. The challenges and changes affect the global socioeconomic and human wellbeing at once or through time. These gradually have a stronger impact on low-income countries like Ethiopia wherein the country has the low and noninstitutionalized capacity to overcome the challenges. In fact, dependence on rain-fed agriculture, low economic development, deforestation, land degradation, and larger and denser human settlements increased Ethiopia's vulnerability to environmental stressors. With the abovementioned motivation, the objective of this paper is a systematic investigation of the nexus between environmental education theory and its practice as a target of exploration of the link between conception and implementation of environmental education for environmental security and sustainable development in Ethiopia. To scrutinize and consolidate the experiences of ORDA indicated in environmental education, international agreements, protocols, and conventions are revisited as the conceptual framework to investigate the case under study. Most of them are global instruments applied to NGOs of community-based projects in developing countries like Ethiopia. Besides, national environment policies, proclamations, and laws are considered to make a juxtaposition alignment with the local environmental and development NGO engaged in the context wherein the programs are implemented. The concern is how environmental education is a strategic tool to boost up the environmental and developmental knowledge, skills, awareness, and attitudes of the stakeholders. Moreover, ORDA's project documents, strategic plan, and implementation reports are discussed in the conceptual frameworks of environmental education. Furthermore, the article in a holistic way incorporated the empirical studies on a nonformal environmental education based on the agreements, protocols, conventions, laws, guidelines, policies, and proclamations considered by the Ethiopian government. Empirical studies on the implementation of the actual project are crucial to make a spin of this article. Likewise, the current debate, commitment, and strategy of the African Union Summit 2020, the Blue Economy Strategy, the Agenda 2063, the Davos 2020 World Economic Forum, the UN Agenda 2030, and the Green Economy Strategy in Ethiopia have sought to strengthen the need-based approach of environmental education as the opportunities of the sustainability of environmental security and development in Ethiopia. In the same vein, ORDA's environmental education strategy since its establishment in 1993 could be manifested in many ways. These include training, learning forum used for scaling-up, documenting the experiences of opportunities, challenges, and knowledge management, and institutionalizing an approach used for the purpose of scale-up, empowerment of the community, and knowledge management to gear as input toward another plan. However, the overall investigation of this study shows that there exists a low level of knowledge management and strategic role in building capacities of the regional community in scaling-up of organizational capacities in project design, planning, monitoring, and evaluation. Still, monitoring and evaluation results were not seriously considered for learning and as the management tool for further improvement as one of the learnings and legitimate strategy of the organization. Besides, the overall investigation of environmental education in the stated above international and local frameworks shows that environmental education is not well institutionalized in a local NGO as of ORDA environmental project practices. There is also inconsistency in using environmental education as a strategic tool to improve environmental security and sustainability of development in ORDA. The environmental education strategies are not explicitly visible while planning the projects. The strategies are not consistent, full, and well institutionalized in the organization projects. There are a weak understanding and consideration of its turning point as a potential to ORDA's theory of change principles.

\section{Data Availability}

The data used to support the findings of this study are available from the corresponding author upon request.

\section{Conflicts of Interest}

The author declares that there are no conflicts of interest regarding the publication of this paper.

\section{Acknowledgments}

The author acknowledges the Faculty of Humanities for Research, Postgraduate and Community Services, Bahir Dar University, for providing financial support in conducting 
research for Ph.D.of Media and Communication to fulfil the requirements of my dissertation.

\section{References}

[1] B. Daley, Environmental Issues in Ethiopia and Links to the Ethiopian Economy, The Crown, London, UK, 2015.

[2] A. D. Yeshalem, "Environmental education about, in, and for the environment: the case of two secondary schools in Ethiopia," Unpublished Thesis, Master of Philosophy, University of Oslo, Oslo, Norway, 2013.

[3] C. Horwood, Weak Links: Challenging the Climate \& Mixed Migration Paradigm in the Horn of Africa \& Yemen, Springer, Berlin, Germany, 2020.

[4] Y. Mulugeta, C. Okereke, A. Coke, T. Ginbo, and J. J. Wakeford, "Governing green industrialization in africa: assessing key parameters for a sustainable socio-technical transition in the context of ethiopia," World Development, vol. 13, pp. 279-290, 2019.

[5] M. H. Zikargae, "Analysis of environmental communication and its implication for sustainable development in Ethiopia," Science of the Total Environment, vol. 634, pp. 1593-1600, 2018.

[6] M. H. Zikargae and A. C. Ali, "A critical analysis of Amhara Development Association's development activities with a framework of participatory development communication model," The Internet Journal Language, Culture and Society, vol. 43, pp. 57-65, 2017.

[7] A. C. Ali, S. Sonderling, and S. Sonderling, "Factors affecting participatory communication for development: the case of a local development organization in Ethiopia," Jurnal Komunikasi, Malaysian Journal of Communication, vol. 33, no. 1, pp. 80-97, 2017.

[8] MoEDC EPA., Fdrec. Environmental Policy, EPA and MoEDC, Addis Ababa, Ethiopia, 1997.

[9] T. Holmes and I. Scoones, Participatory Environmental Policy Processes, Institute of Development Studies, Brighton UK, 2000.

[10] UNESCO, "Intergovernmental conference on environmental education," in Tiblsi Declaration: Intergovernmental Conference on Environmental Education, UNESCO, Paris, France, 1977.

[11] G. Talero, "Environmental education and public awareness," 2004.

[12] UNESCO, Intergovernmental Conference on EE. UNEP Tbilisi (USSR), UNESCO, Paris, France, 1978.

[13] U. T. Umoh, "Environmental education and poverty reduction in Africa," Journal of African Business, vol. 11, no. 1, pp. 70-86, 2010.

[14] A. Gough and N. Gough, The SAGE Encyclopedia of Curriculum Studies, Sage Publications, Oaks, CL, USA, 2010.

[15] P. Rennie, Implementing the Environmental Policy in Your School, NSW department of education and training professional support and curriculum Directorate, Bankstown, Australia, 2001.

[16] J. A. Athman and M. C. Monroe, Elements of Effective Environmental Education Programs, ERIC Institute of Education Sciences, Newyork, NY, USA, 1993.

[17] M. C. Monroe, E. Andrews, and K. Biedenweg, "A framework for environmental education strategies," Applied Environmental Education and Communication, vol. 6, pp. 205-216, 2007.
[18] L. Hens, "A case study: the green school project in Flanders," International Journal of Contemporary Engineering and LifeLong Learning, vol. 7, pp. 51-59, 1997.

[19] CEgN, Environmental Education in Canada, Canadian Environmental Grant makers Network (CEgN), Toronto, Canada, 2006.

[20] C. M. Frantz and F. S. Mayer, The Importance of Connection to Nature in Assessing Environmental Education Programs, Elsevier, Amsterdam, Netherlands, 2013.

[21] J. A. Palmer, Environmental Education in the 21st Century: Theory, Practice, Progress and Promise, Routledge, London, UK, 1998.

[22] UNCED, Agenda 21: Promoting Education, Public Awareness and Training, United Nations Conference on Environment \& Development, Rio de Janerio, Brazil, 1992.

[23] ORDA, "Third strategic plan (2009-2013)," 2009.

[24] ORDA, "The second strategic plan (2004-2008)," 2009.

[25] ORDA, "The first strategic plan (1997-2003)," 2009.

[26] ORDA, Annual (January 1 to December 31, 2018) Performance Report, Bahir Dar: ORDA, Bahir Dar, Ethiopia, 2019.

[27] ORDA. (2018). http://www.ordaethiopia.org/index.php/en/ programs.

[28] ORDA, Three Years (FY 2014 TO FY 2016) Achievement Report, Bahir Dar, Ethiopia, 2017.

[29] ORDA, Revised $4^{\text {th }}$ Strategic Plan, Bahir Dar University, Bahir Dar, Ethiopia, 2016.

[30] ORDA, Performance Review of Thethird Five Years (20092013) Strategic Plan, Bahir Dar: Bahir Dar University, Bahir Dar, Ethiopia, 2014.

[31] N. K. Denzin and Y. S. Lincoln, Handbook of Qualitative Research, Sage Publications, Thousand, Oaks, CL, USA, 2nd edition, 2000.

[32] R. K. Yin, Study Research: A Case Study Design and Methods, SAGE Publication, Oaks, CL, USA, 6th edition, 2018.

[33] H. Rahman, "Public involvment on environmental issues in Malaysia with reference to Alor Star," IPCBEE, vol. 16, pp. 90-93, 2011.

[34] B. Yared, Environmental Problems and Solutions in Ethiopia Generally and in Africa Specifically. A Case Study on Ethiopia, Jimma University, Jimma, Ethiopia, 2009.

[35] J. Creighton, "The public participation handbook making better decision throgh citizen involvment," 2005.

[36] R. A. Johns and R. Pontes, "Parks, rhetoric and environmental education: challenges and opportunities for enhancing ecoliteracy," Journal of Outdoor and Environmental Education, vol. 22, no. 1, pp. 1-19, 2019.

[37] G. Myers, "Environmental issues in africa's cities," in Wiley Blackwell Encyclopedia of Urban and Regional Studies, A. Orum, Ed., John Wiley \& Sons, Hoboken, NJ, USA, 2019.

[38] A. L. Mabogunje, "The environmental challenges in subsaharan Africa," Environment: Science and Policy for Sustainable Development, vol. 37, no. 4, pp. 4-10, 1995.

[39] C. Huggins, Africa Environment Tracking: Issues and Developments, African Centre for Technologies Studies, Uganda, East Africa, 2006.

[40] United Nation Economic Commission for Africa (UNECA), "Africa's Blue Economy: a policy handbook," United Nation Economic Commission for Africa, Addis Ababa, Ethiopia, 2016.

[41] C. Wong, M. Goodsite, and O. Hertel, "Responses to air pollution based on historical and current policies in the EU and ASEAN," Global Environment, vol. 3, no. 6, pp. 150-182, 2010. 
[42] Ethiopian Federal Ministry of Education, Education Sector Development Programme V (ESDP V) 2015/16 - 2019/20 G.C. Programme Action Plan, 1-138, Federal Ministry of Education, Addis Ababa, Ethiopia, 2015.

[43] M. H. Zikargae, "A stakeholders' participation process to combat on water hyacinth in Ethiopia: saving lake tana, the source of Blue nile," NAWA Journal of Language and Communication, vol. 12, no. 2, pp. 72-96, 2018.

[44] A. Birhanu, "Factors influencing environmental knowledge, attitude and participatory behavior towards land degradation. The case of injibara secondary and preparatory school, northwestern Ethiopia the case of injibara secondary\& preparatory school, northwestern Ethiopia," Science, Technology and Arts Research Journal, vol. 2, no. 2, pp. 140-147, 2013.

[45] M. Debele and L. Plevyak, Ethiopian Environmental Education from a Utopian Perspective: A Comparative Study of Two Children's Outlooks, Applied Environmental Education and Communication, Newyork, NY, USA, 2017.

[46] A. Delelo, "Efforts to empower teachers in Ethiopia to address local environmental problems: Achievements and limitations," International Research in Geographical and Environmental Education, vol. 18, no. 3, pp. 211-226, 2009.

[47] H. Sulaiman, H. Semegne, and P. N. Ananth, "A study on the environmental education in the metropolis schools of Addis Ababa, Ethiopia," Journal of Environmental Extension, vol. 7, pp. 22-30, 2008.

[48] M. Tesfay, "An assessment of the effect of the environmental education project of ethiopia on teachers' and students' environmental attitudes," Doctoral Dissertation, ProQuest, UMI Dissertations Publishing, Ann Arbor, MC, USA, 1994.

[49] D. K. Waktola, "Challenges and opportunities in mainstreaming environmental education into the curricula of teachers' colleges in Ethiopia," Environmental Education Research, vol. 15, no. 5, pp. 89-605, 2009.

[50] E. Campbell, M. Skovdal, and C. Campbell, "Ethiopian students' relationship with their environment: implications for environmental and climate adaptation programmes," Children's Geographies, vol. 11, no. 4, pp. 436-460, 2013.

[51] M. Y. Worku, S. M. Mengistie, and A. B. Tamiru, "The place of society and societal issues in the education and training policy of Ethiopia: a content analysis," Bahir Dar University Journal of Education, vol. 18, no. 2, pp. 134-152, 2018. 